\title{
THE EXAMINING OF CONSUMERS' PRODUCT PREFERENCES ACCORDING TO THEIR SHOPPING ADDICTION
}

\author{
DOI: 10.17261/Pressacademia.2018.989 \\ JMML- V.5-ISS.4-2018(4)-p.286-310 \\ Yeliz Bas ${ }^{1}$, Mustafa Abdul Metin Dincer ${ }^{2}$, Neslihan Cavlak ${ }^{3}$ \\ ${ }^{1}$ Düzce University, Düzce, Turkey. \\ yelizbas@duzce.edu.tr, ORCID: 0000-0002-8159-1716 \\ 2Pharmacy Trade, Sakarya, Turkey. \\ mtindincer79@gmail.com, ORCID:0000-0002-1065-963X \\ ${ }^{3}$ Namık Kemal University, Tekirdağ, Turkey. \\ neslihancavlak@hotmail.com, ORCID:0000-0002-6712-971X
}

Date Received: September 13, 2018

Date Accepted: December 2, 2018

To cite this document

Bas, Y., Dincer, M. A. M., Cavlak, N. (2018). The examining of consumers' product preferences according to their shopping addiction. Journal of Management, Marketing and Logistics (JMML), V.5(4), p.286-310.

Permemant link to this document: http://doi.org/10.17261/Pressacademia.2018.989

Copyright: Published by PressAcademia and limited licenced re-use rights only.

\section{ABSTRACT}

Purpose- Shopping addictive can be seen in two sub-categories, either locus of purchasing or locus of product. Locus of product shopping addiction represents materialist and impulsive shopping while the locus of purchasing shopping addiction represents addictive and compulsive shopping. In this research, which is carried out according to this typological approach in shopping addiction, it is tried to determine whether there is a variation according to product categories.

Methodology- In this study, which deals with the clothing sector, where shopping habits are seen intensively, changes in gender factors are also examined. The data was collected by using face-to-face questionaire and interview method. Both quantitative and qualitative techniques are used in the study

Findings- According to the results of the analysis, there are differences between men and women in terms of shopping addiction, and it is revealed that certain shopping addiction are preliminary in certain product categories.

Conclusion- All in the study, $37 \%$ of the participants on the basis of shopping tendency had the shopping addiction tendency, and a high majority (116) of them are locus of product shoppers. Parallel with the literature, the majority of the participants consist of people who are impulsive shopping tendency. This number is almost 3 folds the other addiction dimensions. Besides the women the number of men as a shopper is quite high.

Keywords: Compulsive, impulsive, addiction, materialism, shopping.

JEL Classification: M30, M31, L67

\section{INTRODUCTION}

Shopping is a whole of exchanges and covers one of the most important places among the daily activities of the individuals. Shopping becomes one of the basic elements of socializing in addition to meeting the basic needs. In the modern ways of living which are characterized as increase of the freedom of choice, there is an excessive consumption towards certains products through the globalizing capitalism. People may become addicted to certain product in emotional and/ or physical terms (Urry, 2009).

Addiction is among the research fields of areas such as psychology, psychiatry, medicine and public policy. American Association of Psychiatry defines addition in clinical terms as the functional disorders in the brain function, motivation, memory and relevant circuits which lead to biological, psychological, social and mental distress (Martin, Kamins, Pirouz and Davis, 2013). Traditionally the word "addiction" is expressed as addition to certain substances, this being restricted. However, in recent 
years, it could be seen that various behaviors such as sports, sexuality, gambling, video games, shopping and internet use potentially create addiction (Clark and Calleja, 2008). In the marketing literature, addiction is characterized as an obsessed behavior (O'Guinn and Faber, 1989)and defined as a chronic and continuously repeating behavior (Martin, Kamins, Pirouz and Davis, 2013).

Addiction trends are closely related to compulsive, impulsive and materialist consumption trends (Baş, 2016). Compulsive purchasing is an uncontrolled stimulation which continuously forces a person towards purchasing in order to create a temporary relief from psychological distress that arises from depression (Black, 2007). And is defined as a chronic, excessive and repeating purchasing behavior that creates a big reaction towards negative events, emotions or uncontrolled demands. Those who perform compulsive shopping do not shop in order to benefit from the goods and services or meet their requirements. The important thing for them is the pleasure they acquire from the process of shopping itself (O'Guinn and Faber, 1989) Behavioral addictions and chemical addiction have similar characteristics with compulsive purchasing. The primary response of an individual towards the negative events and emotions is shopping. For that reason, compulsive shopping, which is characterized as the emotions of desire, enthusiasm and relief towards purchasing behaviors, supports the idea that it could be thought as a type of behavioral addiction.

The consumer could make unplanned and sudden purchases under the effect of a strong purchasing feeling and a sense of please and excitement after being attracted by the place where he/she is in. Such repetative purchasing behaviors are generally characterized as "impulsive purchasing" (Rook, 1987). In general such type of stimulated purchases could be done by anybody and could lead to problems. However, when such purchasing behaviors start to be repeated much and the amount of purchase becomes excessive and uncontrolled, then this could be characterized as "compulsive purchasing". Compulsive purchasing behavior could lead to psychological, economic, family problems among people, as well as the feeling of guilty (Billieux, Rochat, My Lien Rebetez and Van der Linden, 2008).

Impulsive and compulsive purchasing are the two different purchasing behaviors outside the standards. Whereas compulsive purchasing is a purchasing behavior that is uncontrolled and creates addiction in a person, the impulsive purchasing is a purchasing behavior which is not previously planned and which occurs spontanouesly (Darrat, Darrat and Amyx, 2016). Impulsive purchasing is more hedonic and emotional. It could take place when a consumer is fascinated by a product at a place where he/she likes and purchases it. Impulsive purchasing is a more widespread fact compared to compulsive purchasing. Almost all consumers could demonstrate such type of purchasing behaviors in some situations.

Materialism, which is associated with another addiction trend, is defined from various aspects, however there are two approaches which are fairly accepted in the field of consumer behavior. Belk defines materialism as "the importance put by the consumer on wordly items". At he highest levels of materials, such types of items have a central role in the life of a person and constitute the sources of highest satisfaction and dissatisfaction in a person (Belk, 1984). On the other hand, a second approach suggested by Richins and Dawson (1992) builds materials on personal values and conceptualizes it as a choice made among the material and immaterial life targets (Richens and Dawson, 1992). Richins and Dawson (1992) state that the materialist individuals put the mateiral assets they have at the center of their lives and that they consider these assets as the key to happiness. Social scientists demonstrated many times that individuals who focus on the action of acquiring tangible assets have decreased satisfaction towards life (Richens and Dawson, 1992), that their level of happiness decreases (Belk R., 1985) and they experience higher levels of depression (Kasser and Ryan, 1993). For that reason, materialism is generally considered as a part of dark side of the consumer behaviors (Hirschman, 1991).

As a conclusion, compulsive, materialist and impulsive consumption trends are interrelated. The important point in this study is to demonstrate the points of separation between these dimensions, not their similarities. However, the important point that should be highlighted first in the researches is to determine whether there is any extremism in the consumption tendency. If there is such a trend, the following step is to discover the dimension of such tendency.

The first point of separation for determining at which sub-dimension the addiction of consumers who demonstrate an intense behavior of shopping is present is to related to their demonstration of either product or purchasing oriented shopping behavior. Whereas for people who are locus of product the important issue is what they purchase rather than the process of shopping itself, the important issue for individuals who are locus of purchasing is the fact that they purchase something regardless of what they purchase. In this regard, materialist persons and impulsive persons purchase in a locus of product manner and it is important for them to what extent the products they have represent their appearance and themselves. For compulsive and addicted persons, the shopping process is seen as a pleasing entertainment action and they demonstrate locus of purchase shopping behaviors. For them the important thing is not what they buy, but the action of buying itself. Even many times they could purchase products which they do not need or will not be using at all. 
For making a classification in relation to the shopping addiction of consumers, an assessment should be made on the basis of sub-dimensions after making a separation of shopping focused on product / purchasing. A similar way will be followed in this study and following a method of clustering, the differences in the product preferences of the participants in each cluster are analyzed. In this study, both qualitative and quantitative methods are used. In the first section of the research, quantitative techniques are demonstrated for revealing the shopping addictions of participants and its dimensions, and in the section part, analysis are conducted using qualitative techniques using open ended questions for demonstrating differentiations on the basis of products.

The basic objective of this research is to demonstrate the differences on the basis of product categories within the framework of tendencies in shopping addictions of consumers. In addition to this basic objective it is tried to demonstrate the details of these differences according to the gender factor, which is one of the most important elements of shopping behaviors. Different from the literature, this study classifies the shopping trends of the respondents and examines the changes in product preferences according to this classification.

\section{DATA AND METHODOLOGY}

In this study researchers used mixed method, both qualitative and quantitative methodologies. And in the first step of the study researchers developed a questionnaire which derived from literature and in the second step of the study researchers used quantitative content analysis.

\subsection{Quantitative Methodology}

Face to face survey and interview methods are applied to 600 participants in this study who are selected through convenience sampling method. Due to the existence of erroneous data found in the surveys which are collected as a result of field study, some surveys were excluded from the application and analysis was conducted on 493 surveys. Survey questions comprise closed end questions which identify demographic characteristics and shopping dimensions and open ended questions which try to discover the product preferences.

The shopping addiction of participants in relation to the shopping dimensions is assessed using 5-level grading (5-Always.... 1Never). This scale is adopted from Lorenzi (2008). This scale which is used by Lorenzi in his article was adopted from De Graaf et al (2005) and measures excessive shopping as a living standard. There are 50 expressions in the scale itself. In this study, seven expressions in Table 3 were preferred as the expressions that are most suitable with the purpose of the study.

A scale which was previously developed in order to assess the tendency dimensions of participants in the shopping (Baş, 2016) was used in this study, and the scale assesses the respondents by means of significance differences. Participants who make graded preferences between two mutually opposite expressions demonstrate which tendency is more compared to the general average as a result of this marking. The expressions contain the following differentiation points: Locus of Product approaches (impulsive and materialist consumption) and locus of purchasing approaches (addictive and compulsive consumption). Each approach is evaluated within itself. The shopping typology on which this scale is based is as shown in Figure 1.

Figure 1: Shopping Addictive Tipology (Baş, 2016)

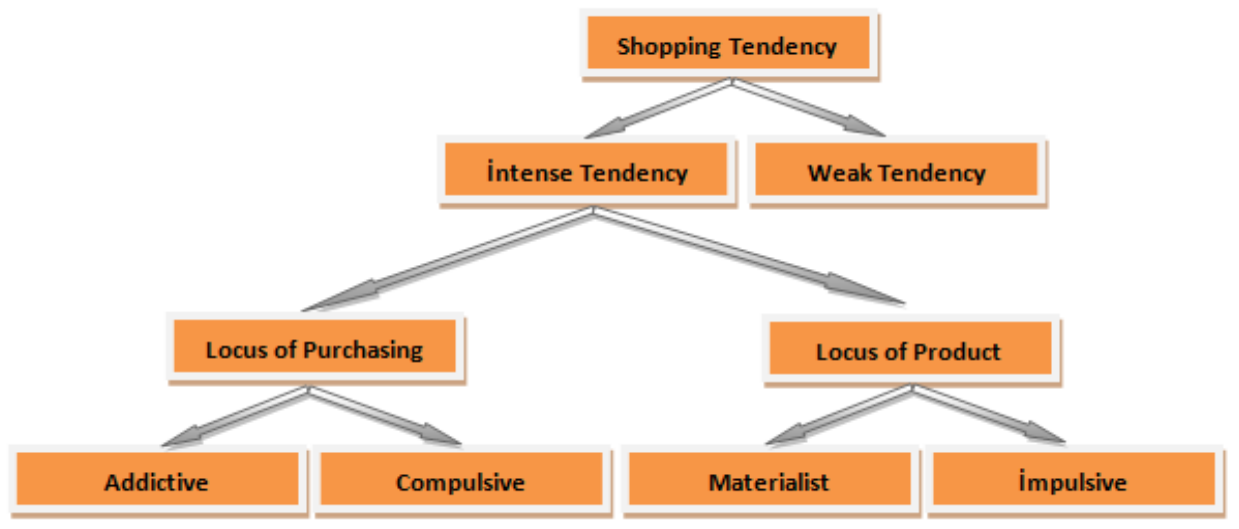

DOI: 10.17261/Pressacademia.2018.989 
The scale is composed of three dimensions. Questions from 1 to 5 in the scale determine the focal point of the participants (product or purchasing focus). The participant could prefer only one choice in each question and marks the extent to which he agrees with such choice. When Table 1 is examined, it could be seen that this scale is a combination of the graded scale and semantic differences scale and it provides the easiness of understanding the marker. If the preference of the consumer is mostly choice B, it could be understood that he is a person who has the tendency of being a locus of purchasing. Questions from 6 to 10 measure the materialist and impulsive consumption slope, and questions from 11 to 15 measure the compulsive and addictive consumption trend. If the participant is intensely a purchasing focus, he is assessed taking into account the answers given to questions from 11 to 15 . If the $B$ choice is mostly preferred for these questions, it could be understood that he has a tendency of addictive consumption. Here the assessment scale is evaluated with the grading approach rather than the number of choices. From this point of view, values from 1 to 6 are given in the same order to the grades from left to right (mostly, sometimes, rarely) (from $A$ choice to $B$ choice) As a result of marking made to expressions included in each group, the clustering analysis is performed and the evaluation is made accordingly. If the cluster values are above 3 , there is a tendency to choice $B$, and if less, there is a tendency to choice $A$. The overview of the scale is as shown in Table 1.

\section{Table 1: Shopping Tendency Scale}

\begin{tabular}{|c|c|c|}
\hline \multirow[t]{2}{*}{1} & $\begin{array}{l}\text { A. It does't matter what I buy, as long as I do shopping. I've } \\
\text { taken something }\end{array}$ & \multirow[t]{2}{*}{ B. I buy if I like. If I'm not impressed enough I don't buy. } \\
\hline & O mostly O sometimes O rarely & \\
\hline \multirow[t]{2}{*}{2} & $\begin{array}{l}\text { A. If I don't have money, I've a credit card. as long as I've } \\
\text { taken something }\end{array}$ & B. If I like or impressed enough I have to buy. \\
\hline & O mostly O sometimes O rarely & $\mathrm{O}$ rarely $\mathrm{O}$ sometimes $\mathrm{O}$ mostly \\
\hline \multirow{2}{*}{3} & A. Being happy is to go shopping & B. Being happy is buying something \\
\hline & O mostly O sometimes O rarely & O rarely $\mathrm{O}$ sometimes $\mathrm{O}$ mostly \\
\hline \multirow[t]{2}{*}{4} & $\begin{array}{l}\text { A. Shopping centres are the places which make me myself. } \\
\text { So where I go is important }\end{array}$ & $\begin{array}{l}\text { B. The items I buy are the things that make me. I am } \\
\text { attentive to what I buy. }\end{array}$ \\
\hline & O mostly $\mathrm{O}$ sometimes $\mathrm{O}$ rarely & $\mathrm{O}$ rarely $\mathrm{O}$ sometimes $\mathrm{O}$ mostly \\
\hline \multirow{2}{*}{5} & A. I've money. So I should spend it. & B. I have money so I can get and buy what I want \\
\hline & O mostly O sometimes O rarely & O rarely $\mathrm{O}$ sometimes $\mathrm{O}$ mostly \\
\hline \multirow[t]{2}{*}{6} & $\begin{array}{l}\text { A. My sense of happiness in the general sense of what I } \\
\text { have or will be of (my acquisitions) }\end{array}$ & B. For a momentary pleasure I buy anything \\
\hline & O mostly O sometimes O rarely & O rarely $\mathrm{O}$ sometimes $\mathrm{O}$ mostly \\
\hline \multirow[t]{2}{*}{7} & $\begin{array}{l}\text { A. In general I buy to increase my possessions.I buy to have } \\
\text { more stuff. }\end{array}$ & B. when I see something and like it I buy it \\
\hline & O mostly O sometimes O rarely & O rarely $\mathrm{O}$ sometimes $\mathrm{O}$ mostly \\
\hline \multirow[t]{2}{*}{8} & $\begin{array}{l}\text { A. I buy without thinking about the consequences of my } \\
\text { possessions }\end{array}$ & B.While I make a purchase I think over on it results \\
\hline & O mostly O sometimes O rarely & O rarely $\mathrm{O}$ sometimes $\mathrm{O}$ mostly \\
\hline \multirow[t]{2}{*}{9} & A. Mostly I feel myself impulsive to buy something. & $\begin{array}{l}\text { B. When I see a product that is different or specific to me } \\
\text { a purchasing impulse occurs on myself }\end{array}$ \\
\hline & O mostly $\mathrm{O}$ sometimes $\mathrm{O}$ rarely & $\mathrm{O}$ rarely $\mathrm{O}$ sometimes $\mathrm{O}$ mostly \\
\hline \multirow[t]{2}{*}{10} & A. My acquisitions (objects or products) reflect who I am. & $\begin{array}{l}\text { B. I buy the products just because I like and it appeal to } \\
\text { me. }\end{array}$ \\
\hline & O mostly O sometimes O rarely & O rarely $\mathrm{O}$ sometimes $\mathrm{O}$ mostly \\
\hline 11 & $\begin{array}{l}\text { A. When I'm shopping, I feel a dilemma about am I doing } \\
\text { right or wrong. }\end{array}$ & $\begin{array}{l}\text { B. I don't think about the results of my shopping. I could } \\
\text { never control myself. }\end{array}$ \\
\hline
\end{tabular}




\begin{tabular}{l|l} 
O mostly O sometimes O rarely & O rarely O sometimes O mostly \\
\hline $\begin{array}{l}\text { A. After shopping, I sometimes regret whether I } \\
\text { exaggerated. } \\
\text { O mostly O sometimes O rarely }\end{array}$ & B. I never regret my shopping \\
O rarely O sometimes O mostly
\end{tabular}

\subsubsection{Quantitative Findings}

Demographic Factors

Table 2: Demographic Factors

\begin{tabular}{|c|c|c|c|c|c|c|c|c|}
\hline & $\mathbf{n}$ & $\%$ & & $\mathbf{N}$ & $\%$ & & $\mathbf{n}$ & $\%$ \\
\hline Marital Status & & & Occupation & & & Education & & \\
\hline Single & 310 & 63 & Official & 41 & 8 & Primary school & 44 & 9 \\
\hline Married & 183 & 37 & Retired & 16 & 3 & High school & 168 & 34 \\
\hline \multirow[t]{2}{*}{ Total } & 493 & 100 & House wife & 57 & 12 & Vocational school & 84 & 17 \\
\hline & & & Self-employment & 54 & 12 & Under graduate & 180 & 36 \\
\hline Gender & & & Student & 114 & 23 & Graduate & 17 & 4 \\
\hline Female & 226 & 46 & Private sector employee & 155 & 31 & Total & 493 & 100 \\
\hline Male & 267 & 54 & Unemployed & 25 & 5 & & & \\
\hline Total & 493 & 100 & Other & 31 & 6 & & & \\
\hline Age & & & Total & 493 & 100 & & & \\
\hline 18 and below & 9 & 2 & Income & & & & & \\
\hline $18-23$ & 139 & 28 & $1.000 \mathrm{TL}$ and below & 57 & 12 & & & \\
\hline $24-29$ & 142 & 29 & $1.001 \mathrm{TL}-1.500 \mathrm{TL}$ & 99 & 20 & & & \\
\hline $30-35$ & 95 & 19 & $1.501 \mathrm{TL}-2.000 \mathrm{TL}$ & 111 & 23 & & & \\
\hline 36 ve 41 & 33 & 7 & $2.001 \mathrm{TL}-2.500 \mathrm{TL}$ & 71 & 15 & & & \\
\hline $42-47$ & 43 & 9 & $2.501 \mathrm{TL}-3.000 \mathrm{TL}$ & 46 & 9 & & & \\
\hline $48-53$ & 21 & 4 & 3.001 TL - 3.500 TL & 47 & 9 & & & \\
\hline 54 and over & 11 & 2 & 3.501 TL and over & 62 & 12 & & & \\
\hline Total & 493 & 100 & Total & 493 & 100 & & & \\
\hline
\end{tabular}




\section{Factor Analysis and Reliability Tests}

In order to speak about the addiction dimensions in the shopping behaviors of the participants, first it is necessary to determine the existence of additions of these participants in relation to the shopping behavior. When considered from this point of view, in the study, the tendencies of participants towards shopping and their behavioral attitudes in shopping (compulsive, impulsive, materialist, addictive) are subjected to separate exploratory factor analysis as mutually independent factors.

The following tables shows the results of factor analysis in relation to each factor, as well as the explained variances, reliability values, averages, standard deviations and sample adequacy values. When the analysis results for all factors are examined, it could be seen that the general reliability values and factor reliabilities and KMO sample adequacy values are at a good level. Besides, whereas it is acceptable that the total explained variance value is above 0.50 , this value seems to be above the acceptance limit.

Table 3: Shopping Tendency Factor Analysis

\begin{tabular}{|c|c|c|c|c|}
\hline \multirow[t]{2}{*}{$\begin{array}{l}\text { Item } \\
\text { Codes }\end{array}$} & Variables (Cronbach Alpha) & 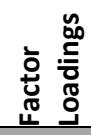 & $\begin{array}{l}\frac{c}{d \pi} \\
\sum \\
\sum\end{array}$ & 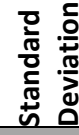 \\
\hline & Shopping Tendency $(0,88)$ & & & \\
\hline A8 & Do you want to buy something constantly? & 0.82 & 2,89 & 1,31 \\
\hline A7 & Do you spend a lot of time shopping? & 0.81 & 2,99 & 1,25 \\
\hline A9 & Do you want to buy more than you have? & 0.78 & 2,87 & 1,42 \\
\hline A3 & Do you sometimes go to the mall just to look around, with nothing specific to buy? & 0.76 & 3,05 & 1,21 \\
\hline A1 & Do you ever use shopping as "therapy"? & 0.76 & 3,06 & 1,35 \\
\hline A2 & Do you try to impress people with what you own? & 0.71 & 2,83 & 1,36 \\
\hline A4 & Have you ever gone on a vacation primarily to shop? & 0.69 & 2,74 & 1,3 \\
\hline A6 & Are any of your credit cards went over the limit? & 0.57 & 2,48 & 1,32 \\
\hline A5 & Have you ever lied to a family member about the amount you spent for a product? & 0.53 & 2,13 & 1,23 \\
\hline
\end{tabular}

Factors created as a result of exploratory factor analysis are tested with confirmatory factor analysis and their adequacy values are controlled. When the variables which examine the shopping tendencies of the participants are subjected to confirmatory factor analysis, the model adequacy values are determined as follows: $X^{2} / \mathrm{sd}: 3.2, \mathrm{NFI}: 0,97, \mathrm{RFI}: 0,95, \mathrm{TLI}: 0,97, \mathrm{CFI}: 0,98$ and RMSEA:0,06. The exploratory factor analysis results for the variables pertaining to the dimension of shopping addiction, which will be examined following the determination of shopping trends of the participants, are as shown in Table 4 . Besides, Table 5 includes confirmatory factor analysis model adequacy values.

Table 4: Shopaholism Dimension Factor Analysis

\begin{tabular}{|c|c|c|c|c|c|c|c|}
\hline Variables (Cronbach Alpha) & Factor Loadings & 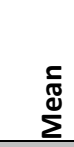 & 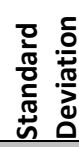 & Variables (Cronbach Alpha) & Factor Loadings & $\begin{array}{l}\mathbf{\Xi} \\
\stackrel{\mathbb{\pi}}{\Sigma} \\
\end{array}$ & 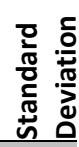 \\
\hline Locus of Shopping $(0,81)$ & & & & Locus of Purchasing $(0,62)$ & & & \\
\hline L1 & 0,83 & 4,6 & 1,7 & L11 & 0,67 & 3,1 & 1,5 \\
\hline L2 & 0,79 & 4,5 & 1,5 & L12 & 0,55 & 3,9 & 1,7 \\
\hline L3 & 0,59 & 4,01 & 1,6 & L13 & 0,69 & 3,2 & 1,6 \\
\hline
\end{tabular}




\begin{tabular}{|c|c|c|c|c|c|c|c|}
\hline L4 & 0,78 & 4,6 & 1,7 & L14 & 0,53 & 3,2 & 1,6 \\
\hline L5 & 0,77 & 4,4 & 1,5 & L15 & 0,73 & 3,1 & 1,4 \\
\hline \multicolumn{4}{|c|}{ KMO: 0.83 , Explained Variances: 0,57} & \multicolumn{4}{|c|}{ KMO: 0.72 , Explained Variances: 0,41} \\
\hline \multicolumn{4}{|c|}{ Locus of Product $(0,59)$} & & & & \\
\hline L6 & 0,05 & 2,8 & 1,7 & & & & \\
\hline L7 & 0,81 & 4,8 & 1,5 & & & & \\
\hline L8 & 0,68 & 4,6 & 1,5 & & & & \\
\hline L9 & 0,78 & 4,6 & 1,6 & & & & \\
\hline L10 & 0,71 & 4,3 & 1,9 & & & & \\
\hline
\end{tabular}

KMO: 0.74, Explained Variances: 0,44

Table 5: Shopaholism Dimensions Confirmatory Factor Analysis Model Fit Results

\begin{tabular}{|c|c|c|c|c|c|c|}
\hline Measurement & CMIN/DF & NFI & RFI & TLI & CFI & RMSEA \\
\hline Locus of Shopping & 2,78 & 0,98 & 0,96 & 0,97 & 0,99 & 0,06 \\
\hline Locus of Product & 1,41 & 0,99 & 0,98 & 0,99 & 0,99 & 0,02 \\
\hline Locus of Purchasing & 2,53 & 0,94 & 0,91 & 0,94 & 0,96 & 0,05 \\
\hline
\end{tabular}

The mutual covariance relationships between each sub-factor dimension was tested following the confirmatory factor analysis, and the differences of the dimensions were demonstrated. After these evaluations are made separately for each factor and subdimensions, a covariance evaluation is made between all factors. The following figure 2 is the $1^{\text {st }}$ degree confirmatory factor analysis measurement model. The values in the figure give the regression coefficients and the standardized regression coefficients not show in the figure are as follows: Locus of Shopping - Locus of Product 0.93; Locus of Shopping - Locus of Purchasing 0.03 and Locus of Product - Locus of Purchasing 0.02. These values gave significant results. Namely, there are differences between the factors. The significance values of the model are $X^{2} / \mathrm{sd}: 2.36, \mathrm{NFI}: 0.91, \mathrm{RFI}: 0.89, \mathrm{TLI}: 0.93, \mathrm{CFI}: 0.95$ and RMSEA: 0,05.

When the results of covariance given in Figure 2 below are examined, although the covariance values between the locus of product and locus of shopping dimensions are high, they differentiate from one another in a significant manner. Again here it is necessary to test the distinction validity. For this, the restricted model technique of Bagozzi et al. (1991) is used. According to this technique, the ci-square value of the restricted model is 175.044 and freedom grade is 74 and the $x$-square value of the restricted model is 391.043 and the degree of freedom is 77 . In the difference between these two models, the ci-square value is 215.99 and the degree of freedom is 3 . The ci-square critical value in $\% 5$ significance degree of freedom 3 , is 9.49 . Since 215,99 $>7,82$ null hypothesis is rejected. Namely, there are significant differences between dimensions. 
Figure 2: Shopping Tendency Dimensions Measurement Model ${ }^{1}$

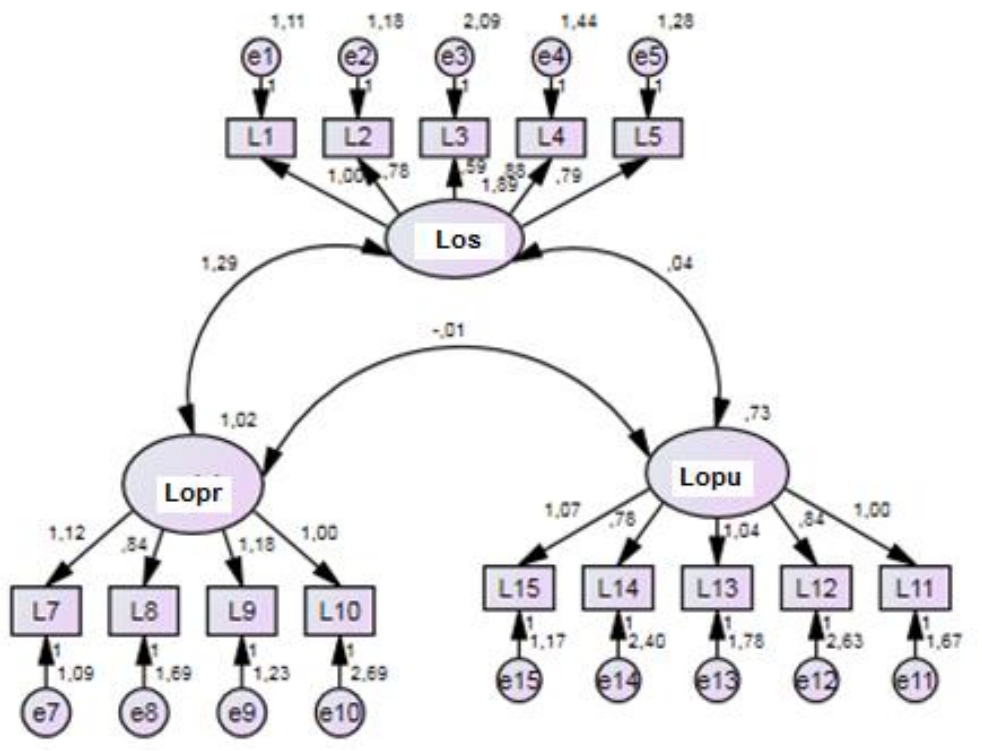

\section{Clustering Analysis}

As it was indicated before, first the existence of shopping tendencies of the participants should be tested in order to discover at which dimensions the tendencies of participants within the context of shopping dimensions are seen more intensely. The scale values used for this are subjected to the clustering analysis and it is defined which participants are in intense shopping behavior. Table 6 gives the results of clustering analysis which classify the shopping trends.

Table 6: Shopping Tendency Clustering Analysis

\begin{tabular}{|c|c|c|c|c|c|c|c|}
\hline \multicolumn{3}{|c|}{ Final Cluster Centers } & \multirow{3}{*}{$\begin{array}{l}\text { Cluster } \\
1 \\
2\end{array}$} & \multirow{2}{*}{$\frac{n}{313}$} & \multirow{2}{*}{ Iteration } & \multicolumn{2}{|c|}{ Central Change } \\
\hline \multirow{2}{*}{ Variables } & \multicolumn{2}{|l|}{ Cluster } & & & & 1 & 2 \\
\hline & 1 & 2 & & 180 & 1 & 3,72 & 3,60 \\
\hline A1 & 2,41 & 4,20 & Total & 493 & 2 & 0,06 & 0,11 \\
\hline A2 & 2,24 & 3,86 & & & 3 & 0,04 & 0,07 \\
\hline A3 & 2,45 & 4,09 & & & 4 & 0,019 & 0,033 \\
\hline A4 & 2,20 & 3,68 & & & 5 & 0.00 & 0.00 \\
\hline A5 & 1,71 & 2,86 & & & & & \\
\hline A6 & 2,05 & 3,21 & & & & & \\
\hline A7 & 2,32 & 4,15 & & & & & \\
\hline A8 & 2,18 & 4,11 & & & & & \\
\hline A9 & 2,14 & 4,13 & & & & & \\
\hline \multicolumn{8}{|l|}{ ANOVA } \\
\hline \multirow{2}{*}{ Variables } & Cluster & & Error & & $F$ & n & \\
\hline & Mean & Sd & Mean & Sd & & $\mathbf{p}$ & \\
\hline
\end{tabular}

${ }^{1}$ Los: locus of shopping; Lopu: locus of purchising; lopr: locus of product 


\begin{tabular}{lllllll} 
A1 & 367,56 & 1 & 1,08 & 491 & 339,73 & 0.00 \\
A2 & 299,29 & 1 & 1,24 & 491 & 241,27 & 0.00 \\
A3 & 308,86 & 1 & 0,86 & 491 & 360,31 & 0.00 \\
A4 & 252,9 & 1 & 1,18 & 491 & 213,76 & 0.00 \\
A5 & 152,24 & 1 & 1,22 & 491 & 125,23 & 0.00 \\
A6 & 155,25 & 1 & 1,43 & 491 & 108,32 & 0.00 \\
A7 & 383,91 & 1 & 0,79 & 491 & 483,27 & 0.00 \\
A8 & 427,69 & 1 & 0,86 & 491 & 496,25 & 0.00 \\
A9 & 453,82 & 1 & 1,11 & 491 & 410,65 & 0.00 \\
\hline
\end{tabular}

1:Weak Shopping 2:Intense Sopping

When Table 6 is examined, expressions from A1 to A9 are measure grading of 5 and values close to 5 point out an intense shopping behavior. Therefore, according to the table, the cluster number 1 represents those who have less shopping tendency and cluster number 2 represents participants with intense shopping tendency. Accordingly, 180 of the participants comprise shopping persons.

In other analysis which could be carried out over 180 shopping participants, the order is followed according to the typology in Figure 1. According to this order, first it is tried to identify whether these 180 shopping participants adopt a purchasing focused or product focused in their purchases. Variables that are between L1 - L5 are measured over a mixed scale being with opposite direction and gradual as it was explained above, and the approaches of the shopper participants are identified with a clustering analysis towards this scale.

Table 7: Locus of Shopping (Locus of Purchasing- Product) Clustering Analysis

\begin{tabular}{|c|c|c|c|c|c|c|c|}
\hline \multicolumn{3}{|c|}{ Final Cluster Centers } & \multirow{3}{*}{$\begin{array}{l}\text { Cluster } \\
1 \\
2\end{array}$} & \multirow{2}{*}{$\frac{n}{64}$} & \multirow{2}{*}{ Iteration } & \multicolumn{2}{|c|}{ Central Change } \\
\hline \multirow{2}{*}{ Variables } & \multicolumn{2}{|l|}{ Cluster } & & & & 1 & 2 \\
\hline & 1 & 2 & & 116 & 1 & 2,9 & 1,97 \\
\hline L1 & 2,26 & 5,57 & Total & 180 & 2 & 0,23 & 0,14 \\
\hline L2 & 2,57 & 5,61 & & & 3 & 0,09 & 0,05 \\
\hline L3 & 2,31 & 4,3 & & & 4 & 0.00 & 0.00 \\
\hline L4 & 2,14 & 5,61 & & & & & \\
\hline L5 & 2,67 & 5,47 & & & & & \\
\hline \multicolumn{8}{|l|}{ ANOVA } \\
\hline \multirow{2}{*}{ Variables } & \multicolumn{2}{|l|}{ Cluster } & \multicolumn{2}{|l|}{ Error } & $\mathbf{F}$ & $n$ & \\
\hline & Mean & Sd & Mean & Sd & & $r$ & \\
\hline L1 & 452,41 & 1 & 1,66 & 178 & 271,33 & 0.00 & \\
\hline L2 & 379,64 & 1 & 1,34 & 178 & 282,57 & 0.00 & \\
\hline L3 & 163,2 & 1 & 3,23 & 178 & 50,41 & 0.00 & \\
\hline L4 & 497,03 & 1 & 1,41 & 178 & 352,08 & 0.00 & \\
\hline L5 & 323,87 & 1 & 1,76 & 178 & 182,99 & 0.00 & \\
\hline
\end{tabular}

2: Locus of Product, 1: Locus of Purchasing

According to Table 7, 116 out of 180 people make locus of product shopping and 64 make locus of purchasing shopping. In the following step, product focused persons will be subjected to clustering analysis among themselves and among persons with 
locus of purchasing and it is tried to identify which addiction dimension they have tendency in accordance with the typology. Results of both these two clustering analysis are given in Table 8 and Table 9.

According to Table 8, 30 people have addictictive tendency and 34 people have compulsive consumption tendency, and according to Table 9, 91 people have impulsive tendency and 25 have materialist consumption tendencies.

Table 8: Locus of Purchasing Clustering Analysis

\begin{tabular}{|c|c|c|c|c|c|c|c|}
\hline \multicolumn{3}{|c|}{ Final Cluster Centers } & \multirow{3}{*}{$\begin{array}{l}\text { Cluster } \\
1 \\
2\end{array}$} & \multirow{3}{*}{$\begin{array}{l}\mathbf{n} \\
34 \\
30\end{array}$} & \multirow{2}{*}{ Iteration } & \multicolumn{2}{|c|}{ Central Change } \\
\hline \multirow{2}{*}{ Variables } & \multicolumn{2}{|l|}{ Cluster } & & & & 1 & 2 \\
\hline & 1 & 2 & & & 1 & 3,76 & 3,07 \\
\hline L11 & 2,17 & 4,73 & Total & 64 & 2 & 0,12 & 0,18 \\
\hline L12 & 2,38 & 3,76 & & & 3 & 0,1 & 0,14 \\
\hline L13 & 2,2 & 3,96 & & & 4 & 0,2 & 0,25 \\
\hline L14 & 2,94 & 2,63 & & & 5 & 0,1 & 0,11 \\
\hline \multirow[t]{2}{*}{ L15 } & 2,35 & 4,66 & & & 6 & 0,14 & 0,16 \\
\hline & & & & & 7 & 0.00 & 0.00 \\
\hline \multicolumn{8}{|l|}{ ANOVA } \\
\hline \multirow{2}{*}{ Variables } & Cluster & & Error & & F & $n$ & \\
\hline & Mean & Sd & Mean & Sd & & $p$ & \\
\hline L11 & 104,19 & 1 & 1,948 & 62 & 53,47 & 0.00 & \\
\hline L12 & 30,54 & 1 & 2,69 & 62 & 11,31 & 0.00 & \\
\hline L13 & 49,41 & 1 & 2,39 & 62 & 20,62 & 0.00 & \\
\hline L14 & 1,51 & 1 & 3,07 & 62 & 0,49 & 0.00 & \\
\hline L15 & 85,31 & 1 & 1,55 & 62 & 54,85 & 0.00 & \\
\hline
\end{tabular}

2: Addictive1: Compulsive

Table 9: Locus of Product Clustering Analysis

\begin{tabular}{|c|c|c|c|c|c|c|c|}
\hline \multicolumn{3}{|c|}{ Final Cluster Centers } & \multirow{2}{*}{$\begin{array}{l}\text { Cluster } \\
1\end{array}$} & \multirow{2}{*}{$\frac{n}{25}$} & \multirow{2}{*}{ Iteration } & \multicolumn{2}{|c|}{ Central Change } \\
\hline \multirow{2}{*}{ Variables } & \multicolumn{2}{|l|}{ Cluster } & & & & 1 & 2 \\
\hline & 1 & 2 & 2 & 91 & 1 & 3,94 & 5,95 \\
\hline L7 & 5 & 5,64 & & & 3 & 1,3 & 0,29 \\
\hline L8 & 4,16 & 5,032 & & & 4 & 0,64 & 0,17 \\
\hline L9 & 4,28 & 5,61 & & & 5 & 0,23 & 0,061 \\
\hline L10 & 1,36 & 5,89 & & & 6 & 0.00 & 0.00 \\
\hline \multicolumn{8}{|l|}{ ANOVA } \\
\hline \multirow{2}{*}{ Variables } & \multicolumn{2}{|l|}{ Cluster } & \multicolumn{2}{|l|}{ Error } & $F$ & $n$ & \\
\hline & Mean & Sd & Mean & Sd & $r$ & $\mathbf{p}$ & \\
\hline L7 & 8,24 & 1 & 1,26 & 114 & 6,49 & 0.00 & \\
\hline L8 & 14,94 & 1 & 2,03 & 114 & 7,33 & 0.00 & \\
\hline L9 & 34,4 & 1 & 1,79 & 114 & 19,14 & 0.00 & \\
\hline L10 & 402,47 & 1 & 0,19 & 114 & 2024,71 & 0.00 & \\
\hline
\end{tabular}

2: Impulsive1: Materialist 


\subsection{Qualitative Methodology}

In the second step of the study researchers used qualitative research method. To this end researchers used open-ended questions at the end of the questionnaire. These open-ended questions derived from four shopaholism dimensions which are impulsive, compulsive, materialist and addictive consumption behaviors.

In the literature content analyses is composed of two dimensions which are quantitative/syntax and qualitative/semantics content analyses. Semantics part of analysis is based on the meaning of the content and it constitutes the qualitative part of the content analysis. In this section the meaning of a word, a sentence, a paragraph or whole text can be used for the analysis. But sentaxial part of the analysis is based on frequency analysis and it constitutes the quantitative part of the content analysis (Gökçe, 2006). In our study we used quantitative content analysis method. For the analysis of the content researchers should build some codes and categories and according to Carla Willig (2008: 35) "Categories can be at a low level of abstraction, in which case they function as descriptive labels (or concepts; see Strauss and Corbin 1990: 61). For example, references to 'anxiety', 'anger' and 'pity' can be grouped together under the category heading of 'emotions'". In the content analysis we followed both deductive and conductive strategies. Due to our conceptual tools, we followed deductive strategy in the content analysis, and we have some pre-codes and themes: our categories or themes are impulsive, compulsive, materialist and addictive consumption behaviors which are taken from literature and the research scale. The codes of these categories: Shoes Bag - watch - electronics - personal care products - jewelry and accessories - top wear - under wear - suit wear. At the same time we used inductive strategy as we built new codes in the analyzing process, due to the open coding method (in-vivo coding). These new codes which created with in-vivo codes: Sewing/needlework and hobby equipment - culture and art products souvenirs - cigarettes - motorcycle parts and equipment - automobile parts and equipments. Researchers used all these codes in all categories.

The datum gained from documents is analyzed with qualitative analysis software (MAXQDA). Through the software coding and analyzing process of the qualitative content analysis is made easily. Also this software gave some other advantages to the analyzer, such as monitoring and controlling the data easily, and the opportunity to add new codes or remove existingcodes. 
Figure 3: Visual Map of the Category and Codes






\section{General View of the Content Analysis}

In this section we gave the general view of our analysis with MAXQDA tables. Our analyzing tool for shopaholics is composed of 6 main categories which are gender, impulsive, materialist, compulsive, addictive, and general consumption tendency.

Below in the bar graph we classified shopaholics as their gender. Gender is a dimension which is frequently evaluated in the literature. In this study we aimed to understand whether if there is a meaningful distinction in gender issue to among the shopaholics. As you see in the figure 4 the number of the women who participating to this research is higher than the men, $55.4 \%$ and $44.6 \%$ respectively. In our case among the women shopaholics is wider than the men. The reason of this distinction among the two groups, which are men and women, is to differentiate distribution of shopaholics tendency between these two participant groups.

Figure 4: Gender Dispersion

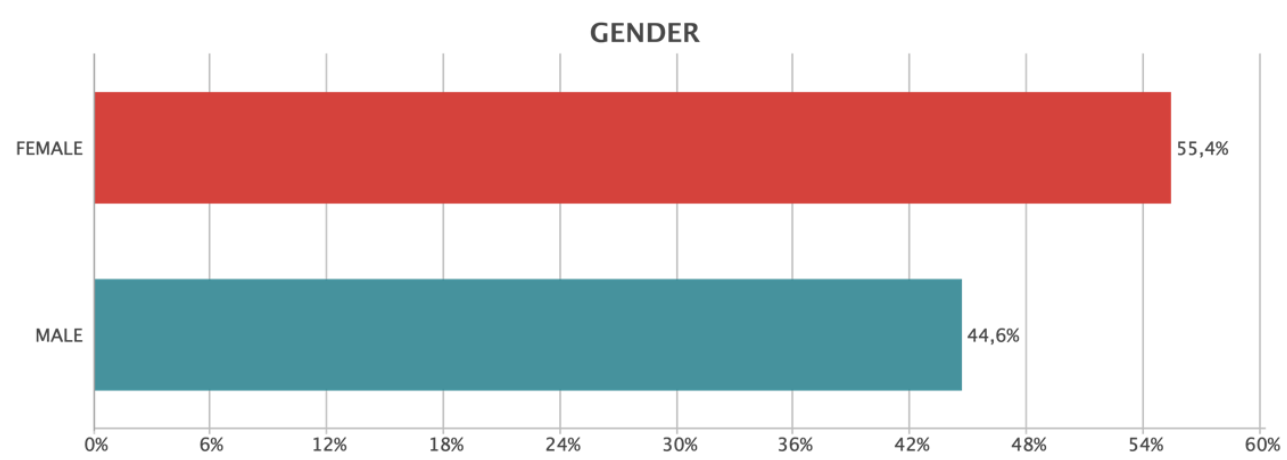

We made three dimensional general consumption tendencies among our participants. In the first bar graph we gave the total distribution of shopaholistic behavior of the participants. Below in figure 5 the top wear, shoes and accessories codes have the highest ranks among the other codes, $54.7 \%, 49.6 \%$ and $35.8 \%$ respectively. To understand the reason of this situation we examined the gender distribution of this consumption tendency. Below in figure 6 and 7 we gave men and women general consumption tendencies.

Figure 5: General Consumption Tendencies

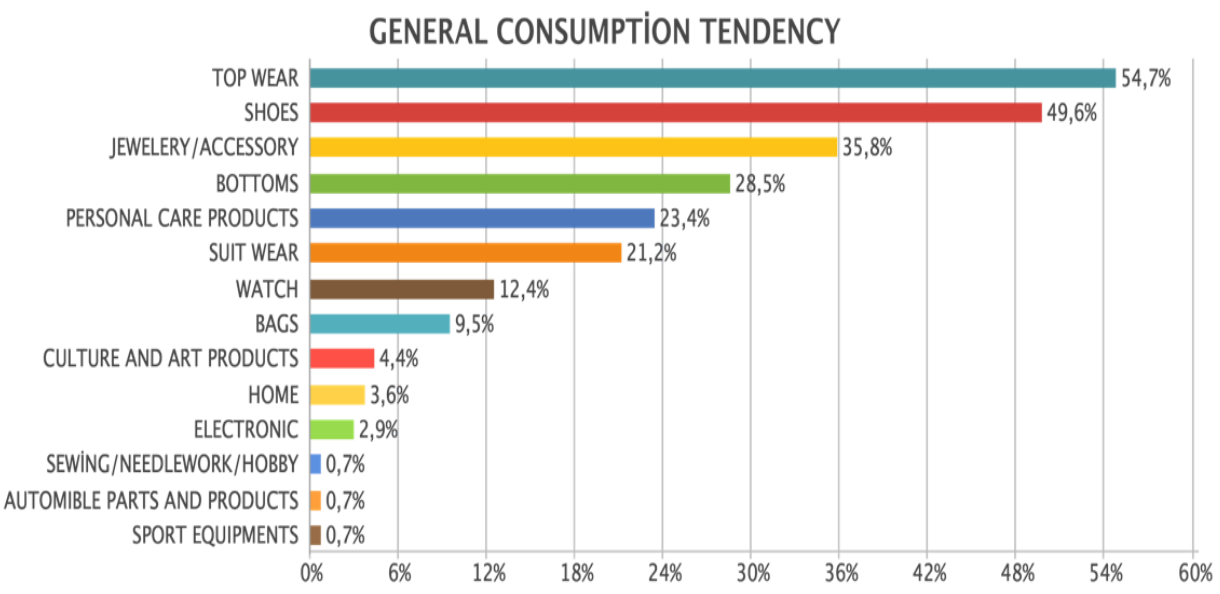


Figure 6: General Consumption

Tendencies of Women



Figure 7: General Consumption

\section{Tendencies of Men}

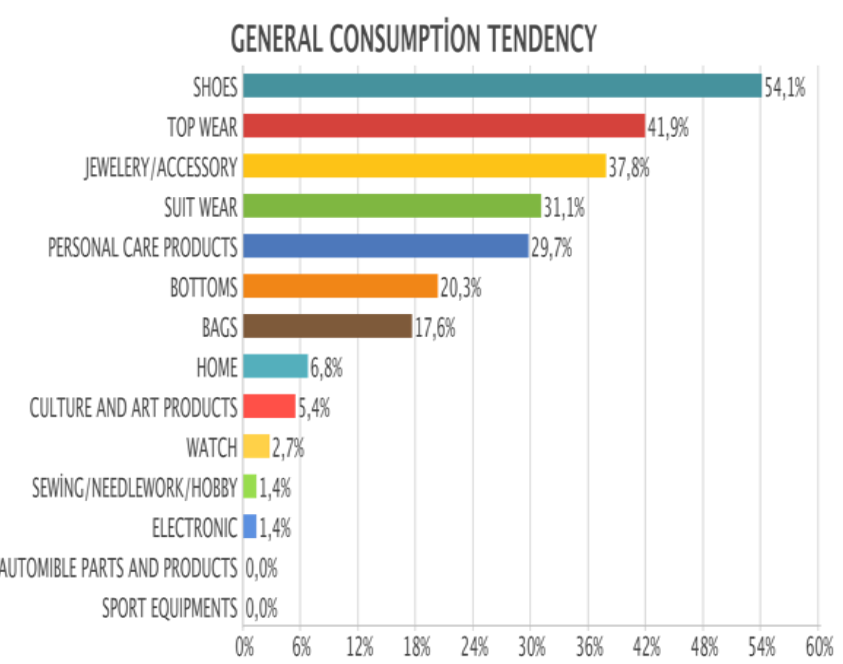

Above in first figure 6 men top wear code has the highest rank among the other codes. In this section the shoe code is the second highest code. In figure 7 there is a distinction between men's and women's tendency. In this category shoe code is the highest rank among the other codes. And top wear is the second highest code. Due to the gender differences these general consumption tendencies show distinction among the participants. We believe that the motivation among the both group stemmed from different orientations. Due to the different fashion orientations women give more importance to the shoes than the men. In the literature scholars have made lots of study about fashion and gender orientation in shopping (eg: Fischer and Arnold,1994: Hansen and Møller Jensen, 2009: Teller and Thomson, 2012: Cho and Workman,2014). Most of these studies empirically validate the relationship between gender, fashion and shopping tendency. According to these studies between men and women in shopping orientation there is a gender based differences. In this section watch code shows dominancy about men's fashion orientation.

As the fashion object men give more importance to the watches than the women. Also in jewellery/accessories, personal care products both groups have different motivations like the previous two codes. In men section "tiepin and rosary" are important figure for the men accessories and perfumes are the dominant personal care products for this section. On the other hand in women section "bracelets, necklaces and brooches" are the important jewellery/ accessory figures for the women. In personal products code cosmetic materials are significant finding for the women. Another interesting finding is suit wear code. Men unlike women have tendency to buy track suits as the pair of sportswear.

Figure 8: General Tendency in Impulsive Category

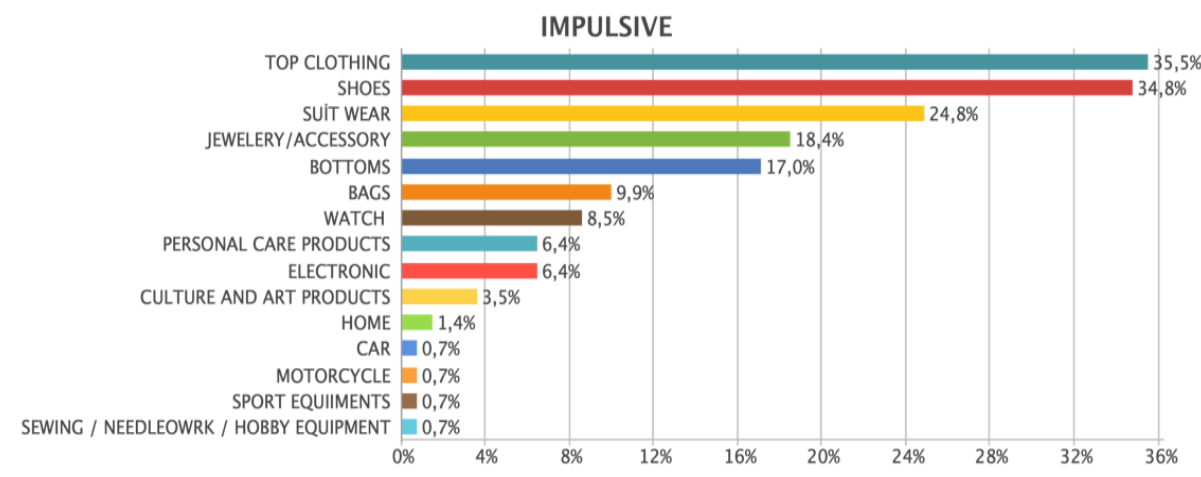

DOI: 10.17261/Pressacademia.2018.989 
Above in figure 8, general tendency in impulsive category, the top wear and shoe codes have almost the same ranks $35.7 \%$ and $35 \%$ respectively. The suit wear and jewelry/accessories codes follow the first two codes with $25 \%$ and $18.6 \%$ percentages respectively. When we look the gender distribution among the women participants, shoe code show dominancy with the 38.5 percent. In this category the top wear code is the second highest code $33.3 \%$. In this section men's impulsive consumption tendency shows reverse characteristics according to the women consumers. We believe that the same reason which we have mentioned above in general consumption tendency about men and women fashion perception differences is valid for this category too.

Figure 9: General Tendency of

\section{Men in Impulsive Category}

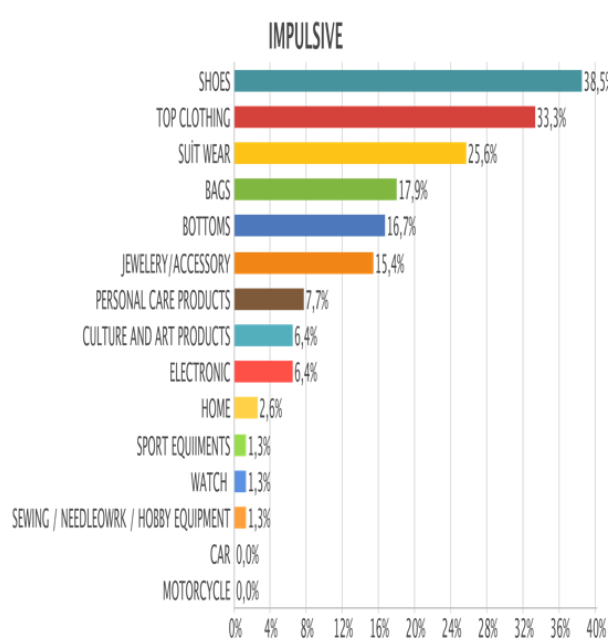

Figure 10: General Tendency of

Women in Impulsive Category

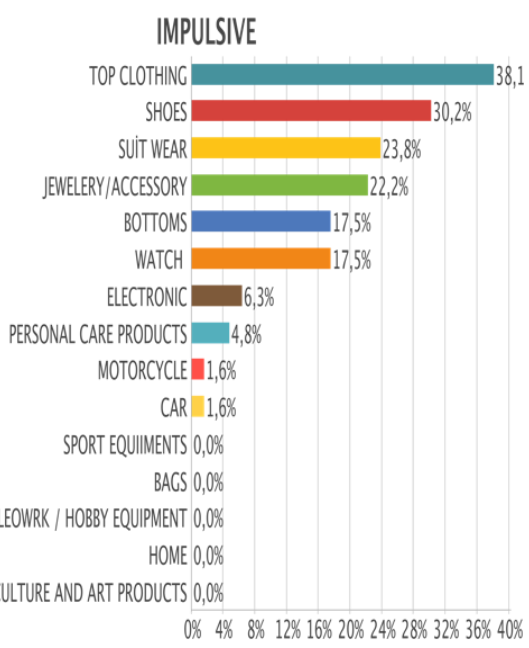

Figure 11: General Tendency of Addictive Consumption

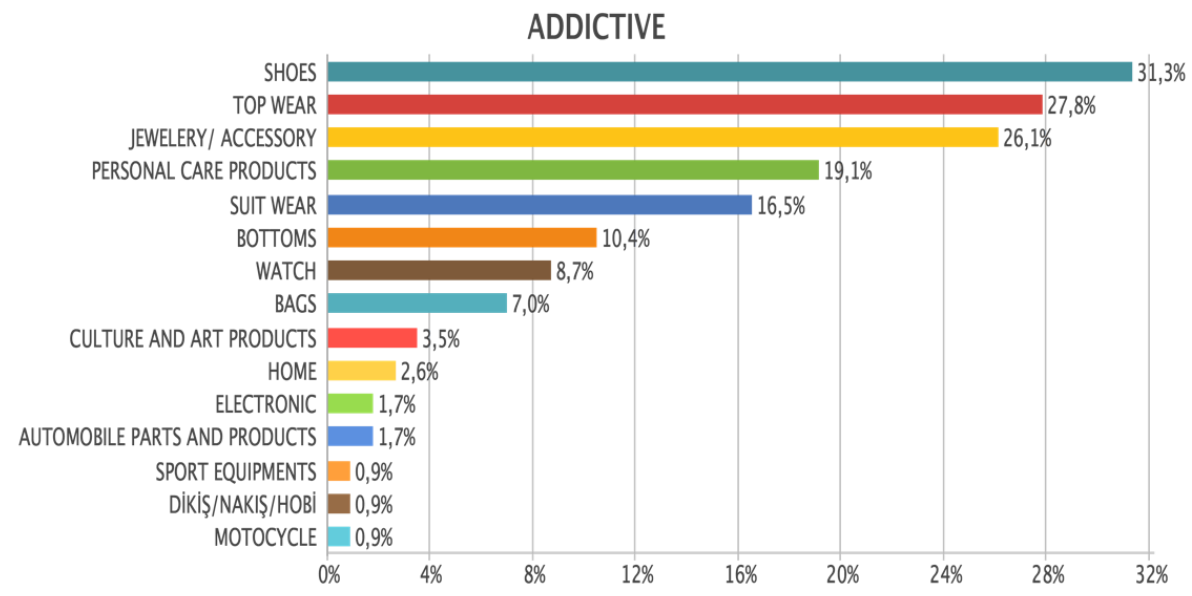

In addictive category the general tendency of addictive consumption is different from impulsive categories. In this category shoe code has the highest rank with $31.3 \%$ percent and the top wear code is the second highest code with $27.8 \%$ percent. Below in figure 12 and 13 the same distinction is valid for these two categories which is based on fashion perception related with gender differences. When we compare the ranking of the code distributions the order of the codes show differences in these two groups.

- $\quad$ The dominant order of code rank in men category: Top wear, shoe, jewelry/accessories, watch, and suit wear. 
- The dominant order of code rank in women category: Shoe, personal care, jewelry/accessories top wear, and suit wear.

As you see in bar graphs in both groups some codes in men group such as home, sewing/needlework/hobby equipment, and bag have no place in the ranking. Also in women group some codes like electronic, sports equipment, and motorcycle parts and equipment have no place in the ranking. Again we believe that the gender differences between these two groups have the dominant effect on shopaholic tendencies.

Figure 12: General Tendency of Men in Addictive Consumption

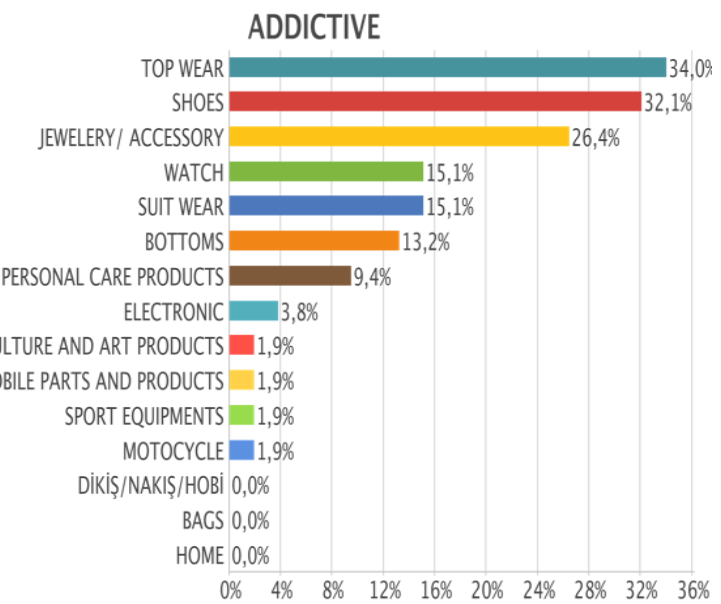

Figure 13: General Tendency of Women in Addictive Consumption

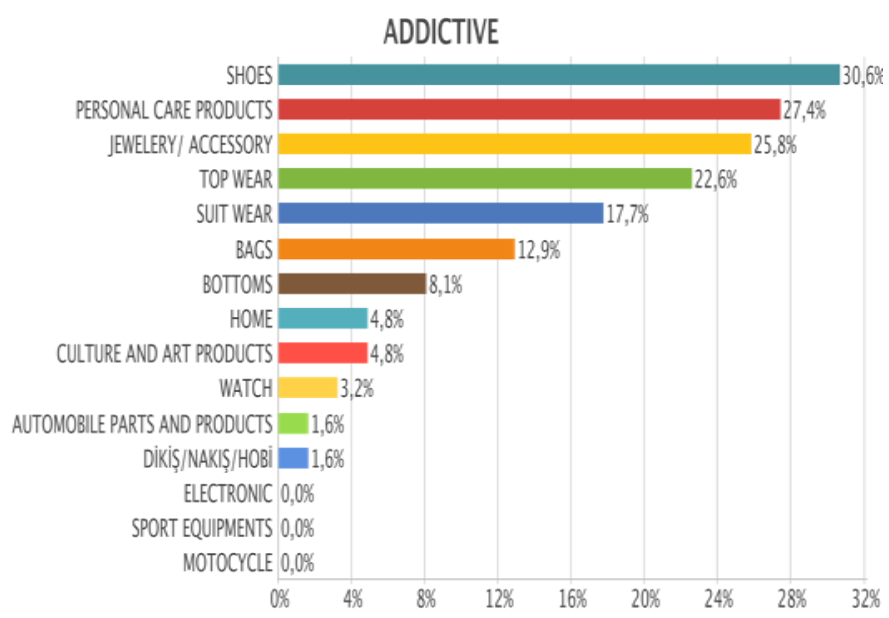


Figure 14: General Tendency of Materialist Consumption

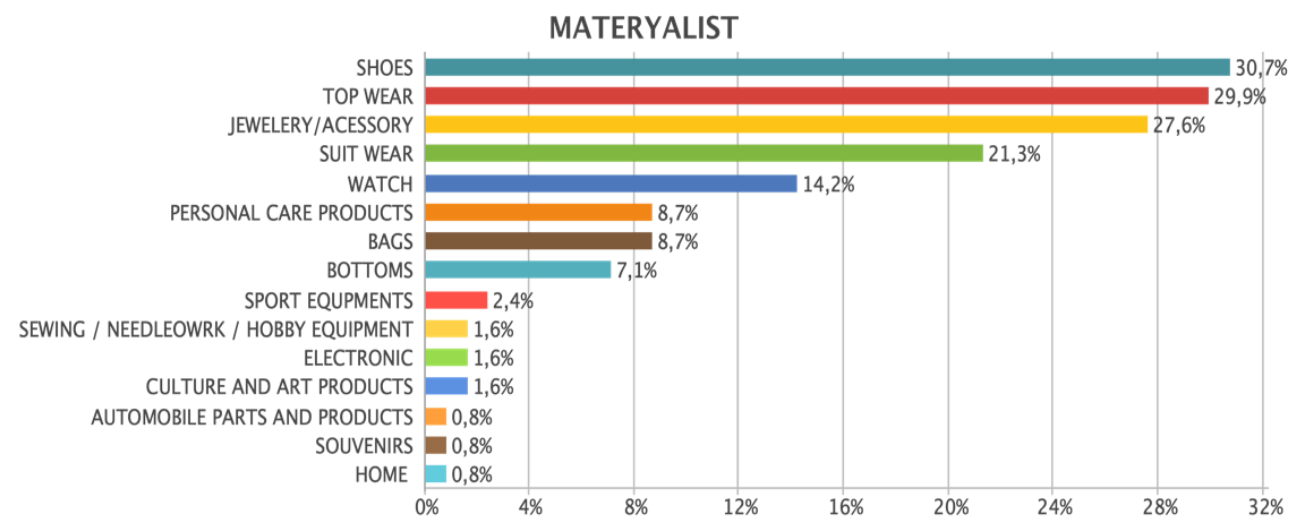

Ranking of the first three code in general tendency of materialist consumption show the similar results with the addictive consumption tendency.

When we examine the gender distribution of the materialists, the ranking of the materialists women shows diversity according to men's materialist ranking. Below in two figures the bar graphs 12 refers to the men group and 13 refers to the women group. In women group except for automobile parts and equipment code they show existence in all codes. In men group due to the gender differences four codes which are home, sewing/needlework/hobby equipment, culture and art products, and souvenirshave no place in the materialist ranking. We believe that the non-existence of culture and art product code in men group should be reviewed as anomaly and examined from cultural dimension.

Figure 15: General Tendency of Men in Materialist Consumption

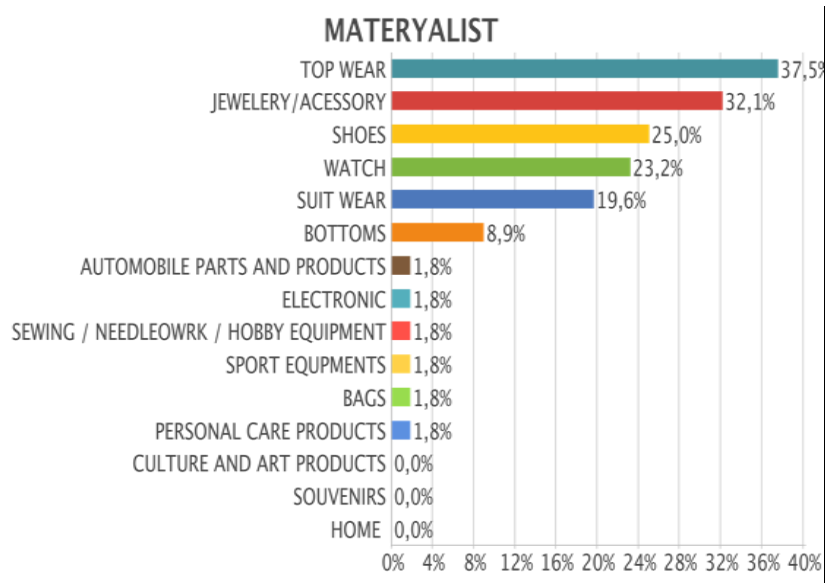


Figure 16: General Tendency of Women in Materialist Consumption

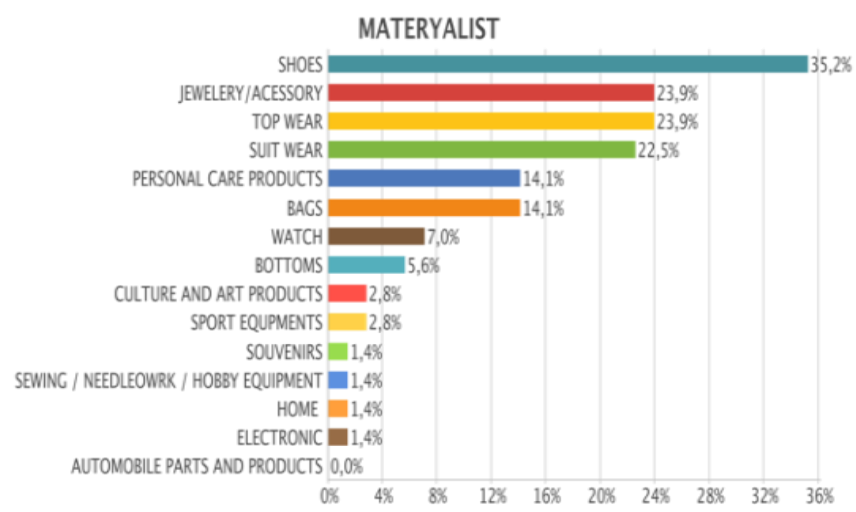

Figure 17: General Tendency of Compulsive Consumption

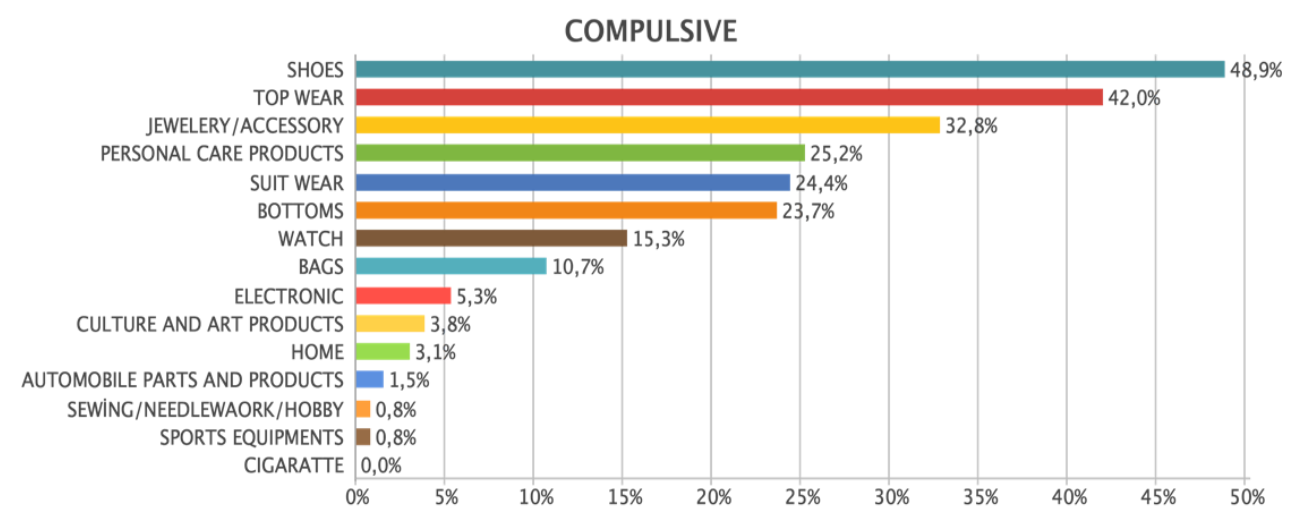

Above in figure 17 the bar graph reveals that the general tendency of compulsive shopaholics. In this category the shoe code is the highest rank like addictive and materialist group. Again in this group the ranking of the first three codes which are shoe, top wear, and jewelry/accessories have the same order. Also in this category the order of the suit wear code is overlapping with the materialist's group order.

Below in figure 18 and 19 we gave the gender distribution of the compulsive consumption tendency category. The bar graph 18 refers to men group and 19 refer to women group.

Figure 18: General Tendency of Men in Compulsive Consumption

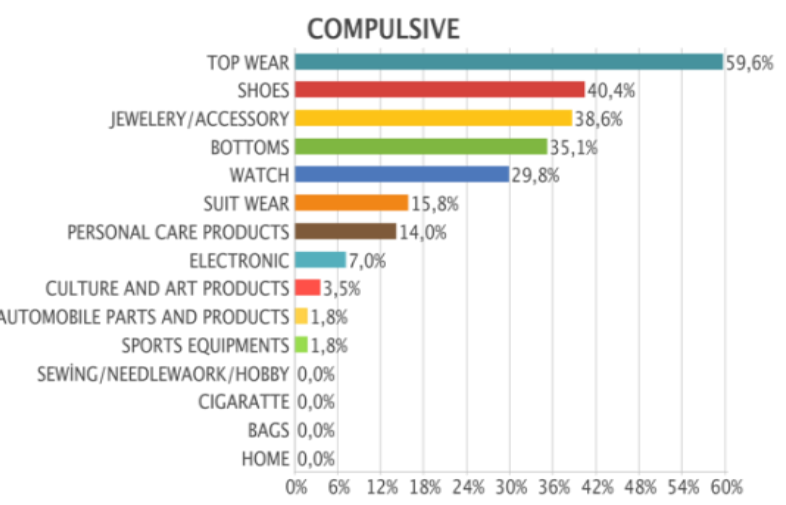

DOI: 10.17261/Pressacademia.2018.989 
Figure 19: General Tendency of Women in Compulsive Consumption

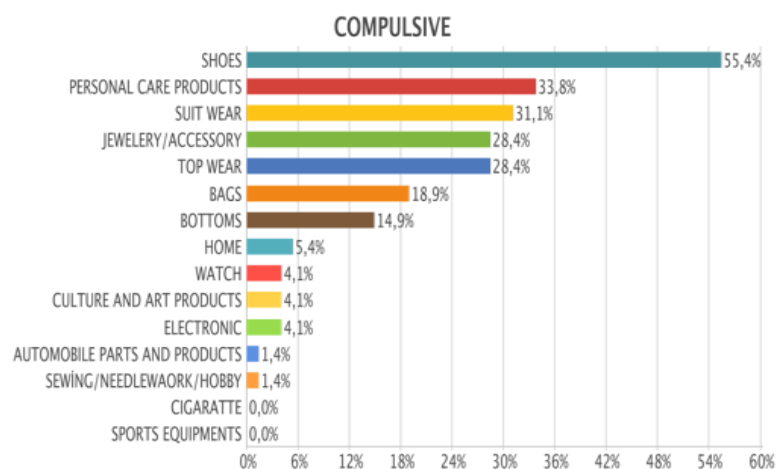

As you see in figure 18 again in men group the gender effects on men shopping behavior reveals as itself an important shopping orientation factor between compulsive groups. In men group due to the gender differences three codes which are home, sewing/needlework/hobby equipment, and bag have no place in the materialist ranking. When we compare the women group distribution of the code is more diverse than the men group. Except for sports equipment code women group exist in all shopping codes. And this situation fortifies our explanation about gender orientation. In table 10 and 11 we gave the comparison between all categories and codes in men and women groups. First table belongs to the men group.

Table 10: Comparison Between All Categories and Codes in Men Group

\begin{tabular}{|c|c|c|c|}
\hline & Men & & Men \\
\hline \multirow[t]{2}{*}{ Impulsive } & $\begin{array}{ll}\text { 1. } & \text { Top Wear } \\
\text { 2. } & \text { Shoe } \\
\text { 3. } & \text { Suit Wear } \\
\text { 4. Jewelry/Accessories } \\
\text { 5. Watch } \\
\text { 6. Electronic } \\
\text { 7. Personal Care } \\
\text { 8. Automobile Parts And Equipment. } \\
\text { 9. }\end{array}$ & Materialist & $\begin{array}{ll}\text { 1. } & \text { Top Wear } \\
\text { 2. Jewelry /Accessories } \\
\text { 3. Shoe } \\
\text { 4. Watch } \\
\text { 5. Suit Wear } \\
\text { 6. Under Wear } \\
\text { 7. Sports Equipment } \\
\text { 8. Personal Care } \\
\text { 9. Bag } \\
\text { 10. Automobile Parts And Equipment. } \\
\text { 11. } \\
\text { Electronic }\end{array}$ \\
\hline & Men & & Men \\
\hline Addictive & $\begin{array}{l}\text { 1. Top Wear } \\
\text { 2. Shoe } \\
\text { 3. Jewelry /Accessories } \\
\text { 4. Watch } \\
\text { 5. Suit Wear } \\
\text { 6. Under Wear } \\
\text { 7. Personal Care } \\
\text { 8. Electronic } \\
\text { 9. Culture And Art Products } \\
\text { 10. Sports Equipment } \\
\text { 11. Automobile Parts And Equipment. } \\
\text { 12. Motorcycle Parts And Equipment }\end{array}$ & Compulsive & $\begin{array}{ll}\text { 1. } & \text { Top Wear } \\
\text { 2. Shoe } \\
\text { 3. Jewelry /Accessories } \\
\text { 4. Under Wear } \\
\text { 5. Watch } \\
\text { 6. Suit Wear } \\
\text { 7. Personal Care } \\
\text { 8. Electronic } \\
\text { 9. Culture And Art Products } \\
\text { 10. Sports Equipment } \\
\text { 11. } \\
\text { Automobile Parts And Equipment. }\end{array}$ \\
\hline
\end{tabular}


As you see in table 10 all sub-categories in men group the top wear code has the highest rank in order. Except for materialist group shoe code is in second place in the ranking. In materialist group Jewelry/Accessories code is in the second place. We believe that the reason of this difference is based on the nature of materialism. According to the Webster "Materialism is the tendency to give undue importance to material interests as contrasted with spiritual concerns; devotion to the material nature and its wants" ( Webster, 2016). Thereby Jewelry /Accessories are of great importance for materialist men to show their wealth on their top.

As you see in table 11 all sub-categories in women group the shoe code has the highest rank in order. Like the men group materialist category in women groupthe Jewelry /Accessories code is in the second place. We believe that the same reason about materialism is valid for this group too. Also these results fortify our explanation about gender differences and fashion issues orientate differently the shopping tendency between women and men.

Table 11: Comparison Between All Categories Aand Codes in Women Group

\begin{tabular}{|c|c|c|c|}
\hline & Women & & Women \\
\hline \multirow[t]{2}{*}{ Impulsive } & $\begin{array}{ll}\text { 1. } & \text { Shoe } \\
\text { 2. } & \text { Top wear } \\
\text { 3. Suit wear } \\
\text { 4. } \\
\text { 5. Ung } \\
\text { 6. Jewelry /accessories } \\
\text { 7. Personal care } \\
\text { 8. Electronic } \\
\text { 9. Culture and Art products } \\
\text { 10. Home } \\
\text { 11. Watch } \\
\text { 12. Sports equipment } \\
\text { 13. Sewing/needlework and } \\
\text { 14. Automobile parts and } \\
\text { hobby equipment } \\
\text { 15. } \\
\begin{array}{l}\text { equipment. } \\
\text { equipment }\end{array}\end{array}$ & Materialist & $\begin{array}{l}\text { 1. Shoe } \\
\text { 2. Jewelry /accessories } \\
\text { 3. Top wear } \\
\text { 4. Suit wear } \\
\text { 5. Bag } \\
\text { 6. Personal care } \\
\text { 7. Watch } \\
\text { 8. Under wear } \\
\text { 9. Culture and Art products } \\
\text { 10. Sports equipment } \\
\text { 11. Electronic } \\
\text { 12. Sewing/needlework and hobby } \\
\text { 13. Home } \\
\text { 14. Souvenirs }\end{array}$ \\
\hline & Women & & Women \\
\hline Addictive & $\begin{array}{ll}\text { 1. } & \text { Shoe } \\
\text { 2. } & \text { Personal care } \\
\text { 3. Jewelry /accessories } \\
\text { 4. } \\
\text { 5. Sop wear } \\
\text { 6. Bag wear } \\
\text { 7. Under wear } \\
\text { 8. Home } \\
\text { 9. Culture and Art products } \\
\text { 10. Watch } \\
\text { 11. Automobile parts and } \\
\text { 12. Sewuipment. } \\
\text { hobby }\end{array}$ & Compulsive & $\begin{array}{ll}\text { 1. } & \text { Shoe } \\
\text { 2. } & \text { Personal care } \\
\text { 3. } & \text { Suit wear } \\
\text { 4. } & \text { Top wear } \\
\text { 5. Jewelry /accessories } \\
\text { 6. Bag } \\
\text { 7. Under wear } \\
\text { 8. Home } \\
\text { 9. Electronic } \\
\text { 10. Culture and Art products } \\
\text { 11. Watch } \\
\text { 12. Sewing/needlework and hobby } \\
\text { 13. Automobile parts and equipment. }\end{array}$ \\
\hline
\end{tabular}




\subsubsection{Qualitative Findings}

In this stage of thr study for both group and their categories we prepared a visual map with MaxQDA software. Below in the first map we gave the code distributions of men group. In the map highly sequenced codes represented with the bold and colored lines for each groups. The most sequenced codes and categories represented with dotted lines.

Below in the figure 20, the top wear code has the highest rank among the other codes and categories. The reason of this massiveness is based on some facts. First, most of the men see top wear as their show case so they give more importance than the other codes. Due to the different fashion orientation which is based on culture and gender, men secondly give importance to their shoes. As they believe that shoe is an important component for their apparel. As you see in the visual map in this category we took the watch codes as a different object from Jewelry/Accessories code. The reason of this distinction is based on man fashion trends and the statement of the participants. On the internet most of the apparel brands and shopping websites differentiate man watch and Jewelry /Accessories. In addition to this reality most of the participants made this distinction in their statements as well. In visual map except for these three common codes there is diversity among the groups. As you see in the visual map this diversity proof us every shopaholic groups have their own shopping pattern and tendency.

\section{Figure 20: Visual Map of the Men Group}

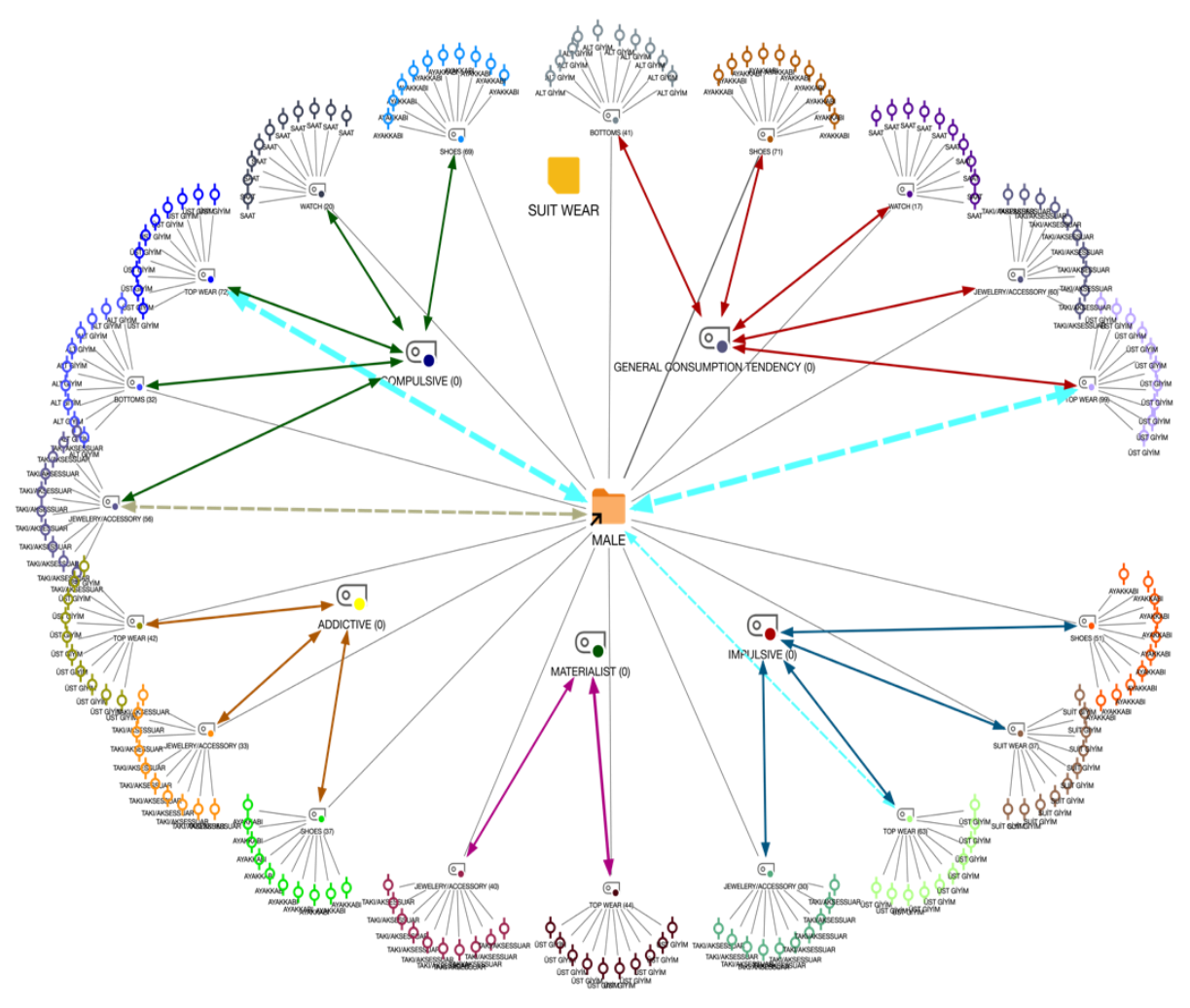

Below in the figure 21, the shoe code has the highest rank among the other codes and categories. The reason of this diversity between men and women group is most of the women use their shoes for fashion oriented. Through this fashion orientation women have the chance to match their shoes with their bag, clothes and jewelry /accessories. Thereby the shopping tendency of the women is more diversive than the men group. 


\section{Figure 21: Visual Map of the Women Group}

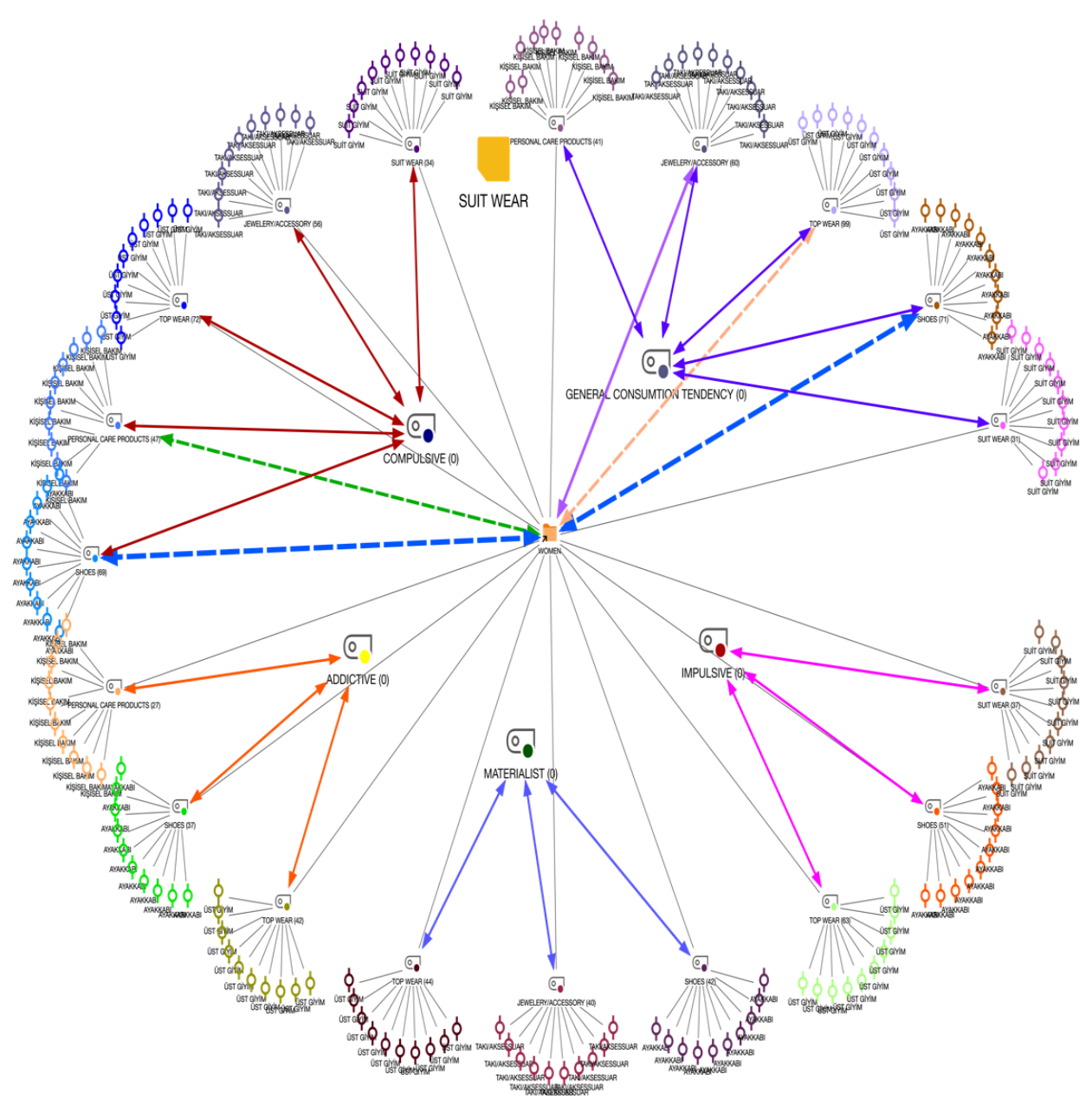

\section{CONCLUSION}

When the findings obtained overall the study, $37 \%$ of the participants on the basis of shopping tendency had the shopping addiction tendency, and a high majority (116) of them are locus of product shoppers. As revealed in the literature, the majority of the participants consist of people who are impulsive shopping tendency. This number is almost 3 folds the other addiction dimensions.

Whereas the shopping addiction of women seems to be higher than men's, the number of men as a shopper is quite high. This reveals the fact that the modern age supports masculine shopping so as to avoid the expression that the "shopping is feminine".

Here women have the tendency towards shoe product category on the basis of their shopping addictions, and upper clothing is more prevalent among men.

Whereas the accessory shopping is in the third line for both of the groups, women concentrate more on necklace, bracelet and brooch, and men concentrate more on watch, tie pinand beads. Besides men prefer shopping on the basis of team in terms of sportswear.

On the basis of general tendencies, the upper wear and shoe product categories are at addiction level at the first line in impulsive and materialist tendencies, the situation changes in the second line. According to this, the second line emphasizes more accessories in materialists and suites in those with stimulations. According to a similar study by Coley and Burgess (2003), 
it was demonstrated that, among 15 product types, women purchased more the clothing products and men purchased electronic products within the context of stimulated shopping behaviors. In addicted and compulsive ones, the first preference is for shoes and the second preference is for upper wear. In the study conducted by Christenson, Faber, de Zwaan and Raymond (1994), it was demonstrated that the compulsive purchasers mostly purchased clothing, jewelry, shoes, cosmetics and similar products by which they could emphasize their external appearances. Similarly, according to Yurchisin and Johnson (2004), compulsive purchasers mostly purchase clothing products and according to another study, they purchase shoes and records as the second preferred items.

When evaluated under the light of the findings, whereas materialist tendencies are highlighted in accessories at a higher rate compared to other tendencies, the impulsive shopping appears different in suite products, and addicted shopping in upper wear and compulsive shopping in shoes.

According to the gender factor, the differences are as women for upper wear and men for suite in impulsive shopping; women for personal care and men for watches in addictive shopping; women for suite and men for underwear in compulsive shopping and women and men for accessory product category in materialist shopping.

The shopping tendencies were determined by applying a preliminary test in the study, and the target mass was tried to be reached through a partially judgmental technique. Within this framework, relatively there is the restriction of numbers. However, it was aimed at reaching the women and men population at a number that is equivalent in terms of gender differences, and it is considered that important results could be obtained in this regard. Since there is a high number of product categories on the basis of general product categories, the research is limited to clothing products. From this point of view, the product segment where the shopping tendencies were seen at the highest rate were preferred. Results obtained within the framework of these restrictions, are parallel compared to similar studies in the literature. According to these results, it is suggested that elements that could be paid attention in clothing categories in terms of shopping addictions sub-dimensions, should be highlighted. In particular it could be beneficial to identify the priorities in some sort of promotion practices such as shop interior design, product showcasing, customer welcoming, showcase design according to this separation of shopping typology in product categories where locus of product and locus of purchasing approach is adopted.

\section{REFERENCES}

Altman, D., Levine, D., Coeytaux, R., Slade, J., Jaffe, R. (1996). Tobacco promotion and susceptibility to tobacco use among adolescents aged 12 through 17 years in a nationally representative sample. Psychopharmacology, Vol.86(11): 1590-1593.

Bagozzi, R., Yi, Y., Phillips, L. (1991). Assessing construct validity in organizational research. Administrative Science Quarterly, vol.36(3): 421-458.

Baş, Y. (2016). Tüketicilerin alışveriş davranışlarındaki düşkünlüklerinin boyutları ve ölçek geliştirme. Journal of Management, Marketing and Logistics, Vol.3/1: 64-86.

Belk, R. (1984). Three scales to measure constructs related to materialism: reliability, validity, and relationships to measures of happiness. Advances in Consumer Research, Vol.11: 291-297.

Belk, R. (1984). Three scales to measure constructs related to materialism: reliability, validity, and relationships to measures of happiness. Advances in Consumer Research Volume 11, eds. Thomas C. Kinnear, Provo, UT : Association for Consumer Research , $291-297$.

Belk, R. (1985). Materialism: trait aspects of living in the material world. Journal of Consumer Research, Vol.12 (3):265-280.

Billieux, J., Rochat, L., My Lien Rebetez, M., Van der Linden, M. (2008). Are all facets of impulsivity related to self-reported. Personality and Individual Differences, Vol.44: 1432-1442.

Black, D. (2007). Compulsive buying disorder: a review of the evidence. CNS Spectrums, Volume 12, Issue $2: 124-132$.

Burroughs, W., Drews, D., Hallman, W. (1991). Predicting personality from personal posessions: a self-presentational analysis. Journal of Social Behavior and Personality, 6 (6): 147-163.

Cho, S., Workman, J. E. (2014). Relationships among gender, fashion leadership, need for affect, and consumers' apparel shopping preference. Family and Consumer Sciences Research Journal, 42(4): 369-385.

Christenson, G., Faber, R., de Zwaan, M., Raymond, N. (1994). Compulsive buying: descriptive characteristics and psychiatric comorbidity. Journal of Clinical Psychiatry, 55 (1): 5-11. 
Clark, M., Calleja, K. (2008). Shopping addiction: a preliminary investigation among Maltese university students. Addiction Research \& Theory, vol.16:6: 633-649.

Cooley, A., Burgess, B. (2003). Gender differences in cognitive and affective impulse buying. Journal of Fashion Marketing and Management, An International Journal, vol.7 (3): 282-295.

Csikszentmihalyi, M. (1999). If we are so rich, why aren't we happy? American Psychologist, 54 (10): 821-827.

Darrat, A., Darrat, M., Amyx, D. (2016). How impulse buying influences compulsive buying: the central role of consumer anxiety and escapism. Journal of Retailing and Consumer Services, (31): 103-108.

Elliott, R. (1994). Addictive consumption: function and fragmentation in postmodernity. Journal of Consumer Policy,17, 159-179.

Fischer, E., Arnold, S. J. (1994). Sex, gender identity, gender role attitudes, and consumer behavior. Psychology \& Marketing, 11(2): 163-182.

Gökçe, O. (2006). İ̧erik analizi - kuramsal ve pratik bilgiler. Siyasal Kitabevi, Ankara.

Grover, A., Kamins, M., Martin, I., Davis, S., Haws, K., Mirabito, A., et al. (2011). From use to abuse: when everyday consumption behaviours morph into addictive consumptive behaviours. Journal of Research for Consumers, $19: 1-8$.

Hansen, T., Møller Jensen, J. (2009). Shopping orientation and online clothing purchases: the role of gender and purchase situation. European Journal of Marketing, 43(9/10): 1154-1170.

Hirschman, E. (1991). Secular mortality and the dark side of consumer behavior: or how semiotics saved my life. Advances in Consumer Research, Vol. 18: 1-4.

Hoch, S., Loewenstein , G. (1991). Time-inconsistent preferences and consumer self-control. Journal of Consumer Research, Volume 17, Issue 4: 492-507.

Jones, M. A., Reynolds, K. E., Weun, S., Beatty, S. E. (2003). The product-specific nature of impulse buying tendency. Journal of Business Research, 56 , 505-511.

Kasser, T., Ryan, R. (1993). A dark side of the American dream: correlates of financial success as a central life aspiration. Journal of Personality and Social Psychology, 65 (August): 410-422.

Lorenzi, P. (2008). Affluence, consumption and the American lifestyle. Soc, vol.45: 107-111, DOI 10.1007/s12115-008-9060-1

Marlatt, G., Curry, S., Gordon, J. (1988). A longitudinal analysis of unaided smoking cessation. Journal of Consulting and Clinical Psychology, 56 (5): 715-720.

Martin, I., Kamins, M., Pirouz , D., Davis, S. (2013). On the road to addiction: the facilitative and preventive roles of marketing cues. Journal of Business Research, Volume 66, Issue 8, 1219-1226.

Moeller, S., Chong, E., Golitsinski, S., Guo, J., McCaffrey, R., Raymond, A., et al. (http://withoutmedia.wordpress.com/.). 24 Hours: UnPlugged.

O'Guinn, T., Faber , R. (1989). Compulsive buying: a phenomenological exploration. Journal of Consumer Research, Volume 16, Issue 2: $147-157$.

Richens, M., Dawson, S. (1992). A consumer values orientation for materialism and its measurement: scale development and validation. Journal of Consumer Research, Vol. 19, Issue 3: 303-316.

Richins, M. (2004). The material values scale: measurement properties and development of a short form. Journal of Consumer Research, Volume 31, Issue 1: 209-219.

Rook, D. W. (1987). The buying impulse. Journal of Consumer Research, Volume 14, Issue 2: 189-199.

Schlosser, S., Black, D., Repertinger, S., Freet, D. (1994). Compulsive buying: demography, phenomenology and comorbidity in 46 subjects. General Hospital Psychiatry, vol.16(3): 205-212.

Sussman, S., Lisha, N., Griffiths, M. (2010). Prevalence of the addictions: a problem of the majority or the minority?. Evaluation \& the Health Professions, Vol 34, Issue 1: 3-56.

Teller, C., Thomson, J. A. (2012). Gender differences of shoppers in the marketing and management of retail agglomerations. The Service Industries Journal, 32(6): 961-980. 
Terry, A., Szabo, A., Griffiths, M. (2004). The exercise addiction inventory: a new brief screening tool. Addiction Research \& Theory, Vol. 12 (5): 489-499.

Underhill, P. (2002). Alışveriş bilimi. Sosyal Yayınları, İstanbul, 255.

Urry, J. (2009). Sociology and climate change. The Sociological Review, 57 (2): 84-100.

Vogt, S., Hunger, A., Türpe, T., Pietrowsky, R., Gerlach, A. (2014). Effects of mood induction on consumers with vs. without compulsive buying propensity: an experimental study. Psychiatry Research, Vol.220: 342-347.

Ward, S., Wackman, D. (1971). Family and media influences on adolescent consumer learning. American Behavioral Scientist, Vol 14, Issue 3, 415-427.

Webster Online Dictionary and Translations http://www.webster-dictionary.org/definition/materialism, ET: 24/11/2016

Willig, C. (2008). Introducing qualitative research methods in psychology, second edition. Maidenhead: McGare Hill/Open University Press.

Yurchisin, J., Johnson, K. (2004). Compulsive buying behavior and its relationship perceived social status associated with buying, materialism, self-esteem and apparel-product involvement. Family and Consumer Sciences Research Journal, vol.32(3): 291-314. 